\title{
Editorial
}

\section{Time for Antarctic scientists to reach out}

I

$\mathrm{n}$ the United States there has been a move afoot to try to stimulate federally funded investigators to

explore meaningful ways of communicating their scientific activities through educational outreach programs. The goal is to help improve the quality of mathematics and science education in both early and secondary education. Dr Rita Colwell, the current Director of the US National Science Foundation (NSF), feels strongly that the time has come for higher education to do its part to help improve precollege science education, a persistent problem in the United States and many other industrialized countries. After all, institutions of higher education stand to benefit by seeing students enter college with sound fundamental science skills, and the taxpayers, who ultimately fund national science programs, benefit from an economy fuelled by both renewed and improved scientific talent.

Dr. Colwell has attacked the problem by establishing new guidelines for peer review of research grants that include meaningful assessments of educational outreach components of proposed or completed research. Moreover, she has developed new systemic programme initiatives including the GK-12 programme that funds stipends for graduate students performing educational outreach activities, and the MSPI program, designed to link school systems and institutions of higher education with the common goal of developing novel curricula to improve mathematics and science education for our next generation of young scientists. Certainly the United States is not alone among countries in its goal to improve math and science education by integrating institutions of higher education in to the process.

Antarctic science lends itself inherently well to educational outreach. It speaks almost romantically to students, through its challenging historical exploration, its essence of discovery, and as one of the final frontiers. Antarctic science is also quintessentially multi- and inter- disciplinary. Lesson plans or learning blocks can be built and integrated around such diverse topics as history, geography, geology, glaciology, palaeontology, oceanography, microbiology, marine biology, and atmospheric physics, to name a few. Thus, Antarctic scientists have a rare opportunity to leverage the general appeal of their discipline to build collaborative coalitions across local school systems, science museums, and media outlets, exploiting such tools as interactive web-based internet technologies. Another innovative approach to promote the allure and importance of Antarctic science is through alternative public educational approaches such as the "Teachers Experiencing Antarctica" and "Artists in Residence" programmes run by the NSF Office of Polar Programs. Similar Artists and Writers programmes are organised by Australia, New Zealand and the UK

While some scientists will argue that their time is better spent publishing papers and writing grants, they may be pleasantly surprised at the level of assistance available within their own institutions, or through federal agencies, that can help provide the resources necessary to foster educational outreach synergies. The fruit borne is well worth the investment. Antarctic scientists should do no less than exploit such opportunities with enthusiasm.

JAMES B.MCCLINTOCK University of Alabama at BiRmingham 